\title{
Taperinha Linnavuori (Hemiptera, Cicadellidae, Deltocephalinae): descrições de nove espécies novas ${ }^{1}$
}

\author{
Keti Maria Rocha Zanol ${ }^{2}$ \\ ${ }^{1}$ Contribuição número 1228 do Departamento de Zoologia, Universidade Federal do Paraná. \\ 2 Departamento de Zoologia, Universidade Federal do Paraná. Caixa Postal 19020, 81531-980 Curitiba, Paraná, Brasil. \\ Bolsista do CNPq.
}

\begin{abstract}
Taperinha Linnavuori (Hemiptera, Cicadellidae, Deltocephalinae): descriptions of nine new species. The following new species are described and illustrated: Taperinha manauara sp. nov., Taperinha concinna sp. nov., Taperinha kijaua sp. nov., Taperinha compta sp. nov., Taperinha tefeigua sp. nov., Taperinha assurinia sp. nov., Taperinha pupejua sp. nov., Taperinha freytagi sp. nov. and Taperinha ourensis sp. nov., from Brazilian Amazonia.

KEY WORDS. Taxonomy.
\end{abstract}

RESUMO. As seguintes novas espécies são descritas e ilustradas: Taperinha manauara sp. nov., Taperinha concinna sp. nov., Taperinha kijaua sp. nov., Taperinha compta sp. nov., Taperinha tefeigua sp. nov., Taperinha assurinia sp. nov., Taperinha pupejua sp. nov., Taperinha freytagi sp. nov. e Taperinha ourensis sp. nov., da Amazônia Brasileira. PALAVRAS CHAVE. Taxonomia.

LinNavUORI (1959) descreveu Taperinha com as espécies T. discigutta (Brasil), T. punctata (Costa Rica, Panamá) e T. bifurcata (Brasil, Bolívia), esta sendo designada como espécie-tipo. Linnavuori \& DeLong (1978) descreveram T. simillima (Bolívia), T. monticola (Peru) e T. adspersa (Bolívia). ZANOL (1988) descreveu T. rugosa, T. flavescens, T. brunneopicta, T. dentata e T. albinoi, todas do Brasil. Zanol (1989) descreveu T. maculata (Peru) e T. excavata (Guiana); ZANol (1997), T. marinonii (Brasil).

As espécies de Taperinha Linnavuori, 1959 têm como características: coroa marfim com duas manchas quadrangulares fulvas ou alaranjadas. Face marrom. Pronoto com duas manchas, de contorno irregular, fulvas, alaranjadas ou amareloouro. Asas anteriores semitransparentes, esbranquiçadas ou fulvas com pontuações marrons.

Cabeça, em vista dorsal, mais longa medianamente do que junto aos olhos; região frontal levemente intumescida e microesculturada; região discal lisa; sutura coronal ultrapassando a metade da coroa; ocelos na margem anterior, visíveis de cima. Frontoclípeo levemente túmido. Anteclípeo levemente mais largo no ápice. Genas com as bordas sinuosas e uma reentrância abaixo dos olhos.

Asas anteriores com três células anteapicais fechadas; veias extranumerárias na margem costal, na célula anteapical central e na primeira célula discal. Clavo com uma veia extranumerária entre $1 \mathrm{~A}$ e a sutura claval e outra entre as veias anais. Apêndice desenvolvido alcançando $M_{3+4}$.

Espinulação das tíbias anteriores $1+4$ e dos fêmures posteriores $2+2+1$.

Pigóforo com apêndices. Valva genital retangular. Placas subgenitais triangulares; macrocerdas em fileira dupla na metade basal e depois unisseriadas. Edeago simétrico e tubular.

O material está depositado no Instituto de Pesquisas da Amazônia, Manaus, Amazonas (INPA); Coleção de Entomologia Pe J.S. Moure, Departamento de Zoologia, Curitiba, Paraná (DZUP); Museu Paraense Emílio Goeldi, Belém, Pará (MPEG); Universidade Federal do Amazonas, Manaus, Amazonas (UFAM).

As medidas são fornecidas em milímetros.

\section{Taperinha manauara sp. nov.}

Figs 1-7

Holótipo macho. Coroa marfim com duas manchas alaranjadas sobre o disco; margem anterior com quatro pequenas manchas marrons: duas junto aos ocelos e duas medianas.

Pronoto marfim com manchas irregulares sobre o disco e na margem anterior, amarelo-ouro. Asas anteriores esbranquiçadas com uma grande mancha marrom-clara, mais ou menos triangular com sua base na margem anal e o ápice na altura da segunda célula discal, mancha esta com pontos marrom-escuros e esparsos, coalescentes nos bordos e duas pequenas áreas arredondadas, esbranquiçadas, junto à margem anal; margem costal com manchas triangulares marrons; células anteapicais central e interna pontuadas de marrom; terceira, quarta e quinta células apicais marrom-claras.

Pigóforo com dois pares de apêndices ventrais, mais ou menos paralelos, voltados para frente: o par proximal com o ápice mais ou menos espatulado e a borda interna serreada. Estilos com ápices levemente côncavos e projetados lateralmente formando um pequeno bico. Edeago tão longo quanto o

Revista Brasileira de Zoologia 21 (2): 337-342, junho 2004 
conetivo, curvo para cima; superfície ventral com pequenas protuberâncias.

Fêmea. Sétimo esterno com a margem posterior sinuosa e um lobo alongado, de cada lado da fenda mediana; fenda estreita atingindo a metade do comprimento da placa.

Comprimento. Macho: 3,96-4,10; fêmea: 4,00-4,60

Material examinado. Holótipo macho do Brasil, Amazonas: Manaus (Reserva Ducke), 02.V.1990. J. Vidal leg. (INPA). Parátipos. Ibidem, 5 machos (INPA); Ibidem, 31.IX.1996, U. Luis leg., 2 machos (DZUP); Ibidem, 9-22.IX.1994, Rafael e Vidal leg., 3 machos, 4 fêmeas (DZUP); Ibidem, 24.IV.1990, J.A. Rafael leg., 1 macho, 1 fêmea (INPA); Ibidem, 14.V.90, Vidal leg., 1 macho (INPA); Ibidem, 11.VI.1990, 1 fêmea (DZUP); Ibidem, 29.VIII. 1988, J. A. Rafael leg. 1 macho (INPA); Ibidem, 22.IX.1988, 1 fêmea (INPA); Ibidem, ZF3 Km 23, Fazenda Esteio Res. 1208, 8.IV.87, B. Klein leg., 2 machos, 4 fêmeas (INPA).

Variação intraespecífica. As manchas marrom-escura da coroa podem não ocorrer. A margem posterior do sétimo esterno da fêmea pode apresentar-se levemente oblíqua e os lobos variar no seu comprimento.

Etimologia. O nome da espécie significa originário de Manaus, onde o material foi coletado.

\section{Taperinha concinna sp. nov.}

\section{Figs 8-11}

Holótipo macho. Coroa marfim com duas manchas alaranjadas sobre o disco.

Pronoto marfim com manchas irregulares sobre o disco e na margem anterior, amarelo-ouro. Asas anteriores esbranquiçadas com uma grande mancha mais ou menos triangular com sua base na margem anal e o ápice na altura da segunda célula discal, mancha esta marrom-clara com pontos marrom-escuros e esparsos, coalescentes nos bordos e duas pequenas áreas arredondadas, esbranquiçadas, junto à margem anal; margem costal com manchas triangulares marrons; células anteapicais central e interna pontuadas de marrom; terceira, quarta e quinta células apicais marrom-claras.

Pigóforo com um apêndice ventral sinuoso, voltado para frente e para fora, de cada lado; borda interna com leves protuberâncias. Estilos com ápice truncado. Edeago mais longo que o conetivo, distintamente curvo para cima.

Fêmea. Sétimo esterno com a margem posterior obliqua e projetada num lobo mediano.

Comprimento. Macho: 4,40; fêmea: 4,42.

Material examinado. Holótipo macho do BrasiL, Amazonas: Querari, 5.IV-27.V.1993, J. Vidal leg. (0033026-INPA). Parátipo. Ibidem, 1 fêmea (0033002-INPA).

\section{Taperinha kijaua sp. nov. \\ Figs $12-15$}

Holótipo macho. Coroa marfim com duas manchas alaranjadas sobre o disco; margem anterior com quatro manchas marrons: duas junto aos ocelos e duas medianas.
Pronoto marfim com duas manchas irregulares amareloouro sobre o disco e três manchas alaranjadas, na margem anterior. Asas anteriores esbranquiçadas com uma grande mancha mais ou menos triangular com sua base na margem anal e o ápice na altura da segunda célula discal, mancha esta marromclara com pontos marrom-escuros e esparsos, coalescentes nos bordos e duas pequenas áreas arredondadas, esbranquiçadas, junto à margem anal; margem costal com manchas triangulares marrons; células anteapicais central e interna pontuadas de marrom; terceira, quarta e quinta células apicais marrom-claras. Clavo com venação alaranjada.

Pigóforo com um apêndice ventral, mais ou menos reto, voltado para frente e para fora, de cada lado. Estilos digitiformes. Edeago mais longo que o conetivo, delgado e curvo para cima; ápice distintamente bífido com os braços divergentes.

Fêmea. Sétimo esterno com a margem posterior sinuosa e uma fenda larga e profunda alcançando a metade do comprimento da placa.

Comprimento. Macho: 4,00; fêmea: 4,58.

Material examinado. Holótipo macho do Brasil, Amazonas: Parque Nacional do Jaú (Seringal), 27.IV-03.V.1996, J. A. Rafael e J. Vidal leg. (0033094-INPA). Parátipo. Ibidem, Rio Jaú, 14.X.1993, J. Vidal leg., 1 fêmea (0033068-INPA).

Etimologia. Kaingang: $k i=$ de $($ origem $)+$ Jaú nome da localidade onde a espécie foi coletada.

\section{Taperinha compta sp. nov.}

\section{Figs 16-19}

Holótipo macho. Coroa marfim com duas manchas alaranjadas sobre o disco; margem anterior com duas manchas medianas amarelo-ouro e duas marrons junto aos ocelos.

Pronoto marfim com duas manchas irregulares amareloouro sobre o disco e três manchas alaranjadas, na margem anterior. Asas anteriores esbranquiçadas com uma grande mancha mais ou menos triangular com sua base na margem anal e o ápice na altura da segunda célula discal, mancha esta marromclara com pontos marrom-escuros e esparsos, coalescentes nos bordos e duas pequenas áreas arredondadas, esbranquiçadas, junto à margem anal; margem costal com manchas triangulares marrons; células anteapicais central e interna pontuadas de marrom; terceira, quarta e quinta células apicais marrom-claras.

Pigóforo com dois pares de apêndices ventrais voltados para frente; o par proximal mais ou menos reto, pontiagudo e o par distal maior, levemente curvo para dentro, com a borda externa e ápice irregularmente denticulado. Estilos digitiformes. Edeago maior que o conetivo, distintamente curvo para cima e com o ápice fendido.

Fêmea. Coroa com duas manchas marrons medianas, junto às manchas amarelo-ouro. Sétimo esterno com a margem posterior côncava e com dois lobos de cada lado da fenda mediana; o lobo interno maior e delgado; fenda ultrapassando a metade do comprimento da placa.

Comprimento. Macho: 4,34; fêmea: 4,40. 


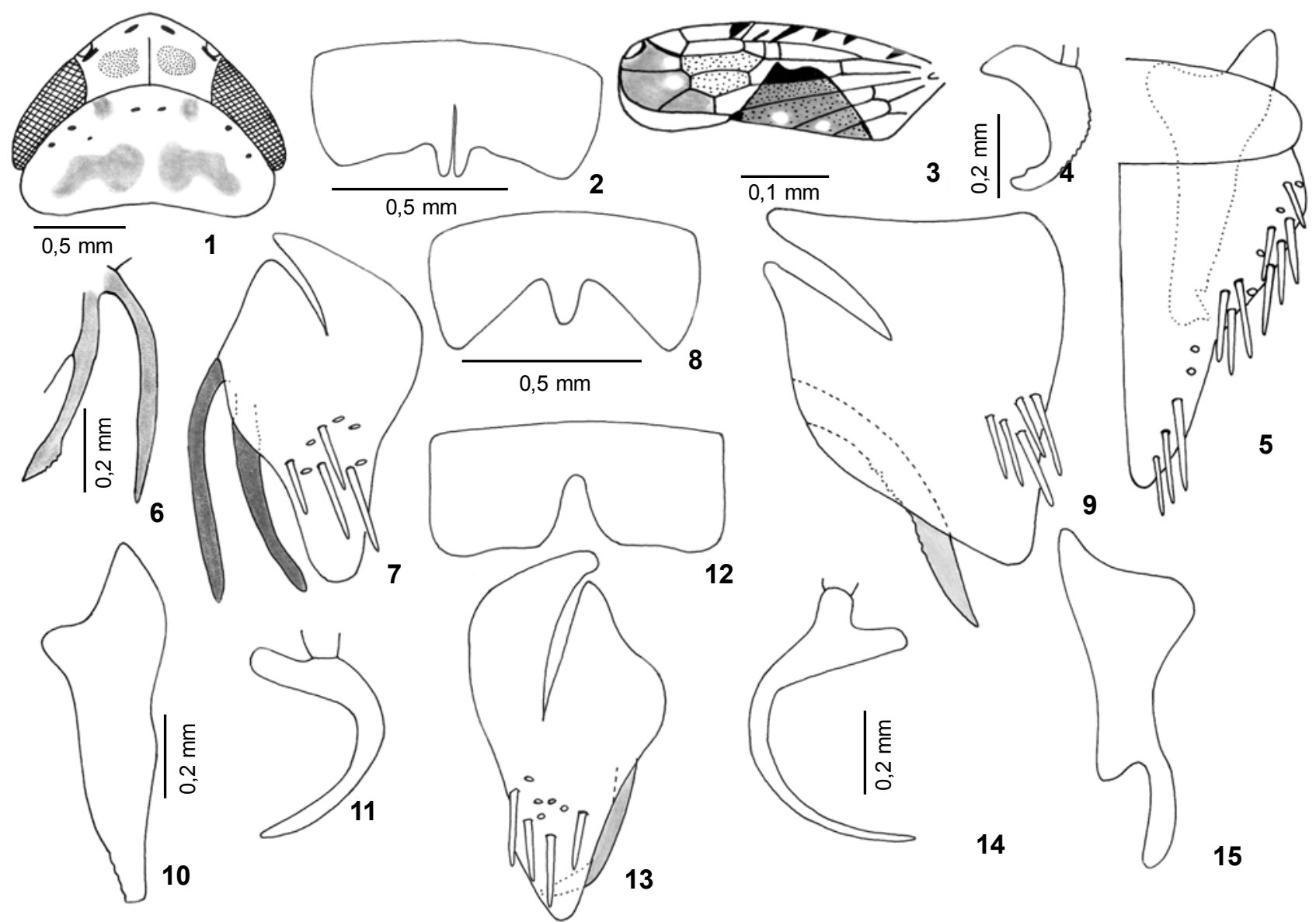

Figuras 1-15. (1-7) Taperinha manauara sp. nov.: (1) cabeça e pronoto, dorsal; (2) sétimo esterno da fêmea; (3) asa anterior; (4) edeago, lateral; (5) valva genital, placa subgenital e estilo; (6) apêndice pigóforo, vista interna; (7) pigóforo, lateral; (8-11) Taperinha concinna sp. nov.: (8) sétimo esterno da fêmea; (9) pigóforo, lateral; (10) estilo; (11) edeago, lateral. (12-15) Taperinha kijaua sp. nov.: (12) sétimo esterno da fêmea; (13) pigóforo, lateral; (14) edeago, lateral; (15) estilo.

Material examinado. Holótipo macho do BrasIL, Rondônia:

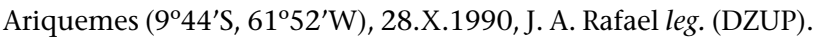
Parátipo. Ibidem, 1 fêmea (DZUP).

\section{Taperinha tefeigua sp. nov. \\ Figs 20-23}

Holótipo macho. Coroa marfim com duas manchas alaranjadas sobre o disco.

Pronoto marfim com manchas irregulares sobre o disco e na margem anterior, amarelo-ouro. Asas anteriores esbranquiçadas com uma grande mancha mais ou menos triangular com sua base na margem anal e o ápice na altura da segunda célula discal, mancha esta marrom-clara com pontos marromescuros e esparsos, coalescentes nos bordos e duas pequenas áreas arredondadas, esbranquiçadas, junto à margem anal; margem costal com manchas triangulares marrons; células anteapicais central e interna pontuadas de marrom; terceira, quarta e quinta células apicais marrom-claras.

Pigóforo com dois pares de apêndices ventrais, mais ou menos espatulados: o par proximal com a borda externa irregularmente recortada e a borda interna, na metade apical, serreada; o par distal curvo, voltado para dentro e para frente com a borda interna irregularmente recortada, no terço apical. Estilos falciformes. Edeago tão longo quanto o conetivo, levemente curvo para cima.

Fêmea. Desconhecida.

Comprimento. Macho: 4,40.

Material examinado. Holótipo macho do Brasil, Amazo-

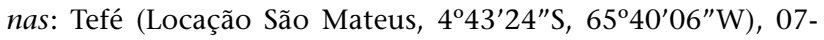
16.IX.1994, P.F. Bührnhein et al. leg. (DZUP).

Etimologia. Tefé (localidade onde o material foi coletado) $+\hat{\imath} g u a($ = natural, em língua Guarani).

Revista Brasileira de Zoologia 21 (2): 337-342, junho 2004 


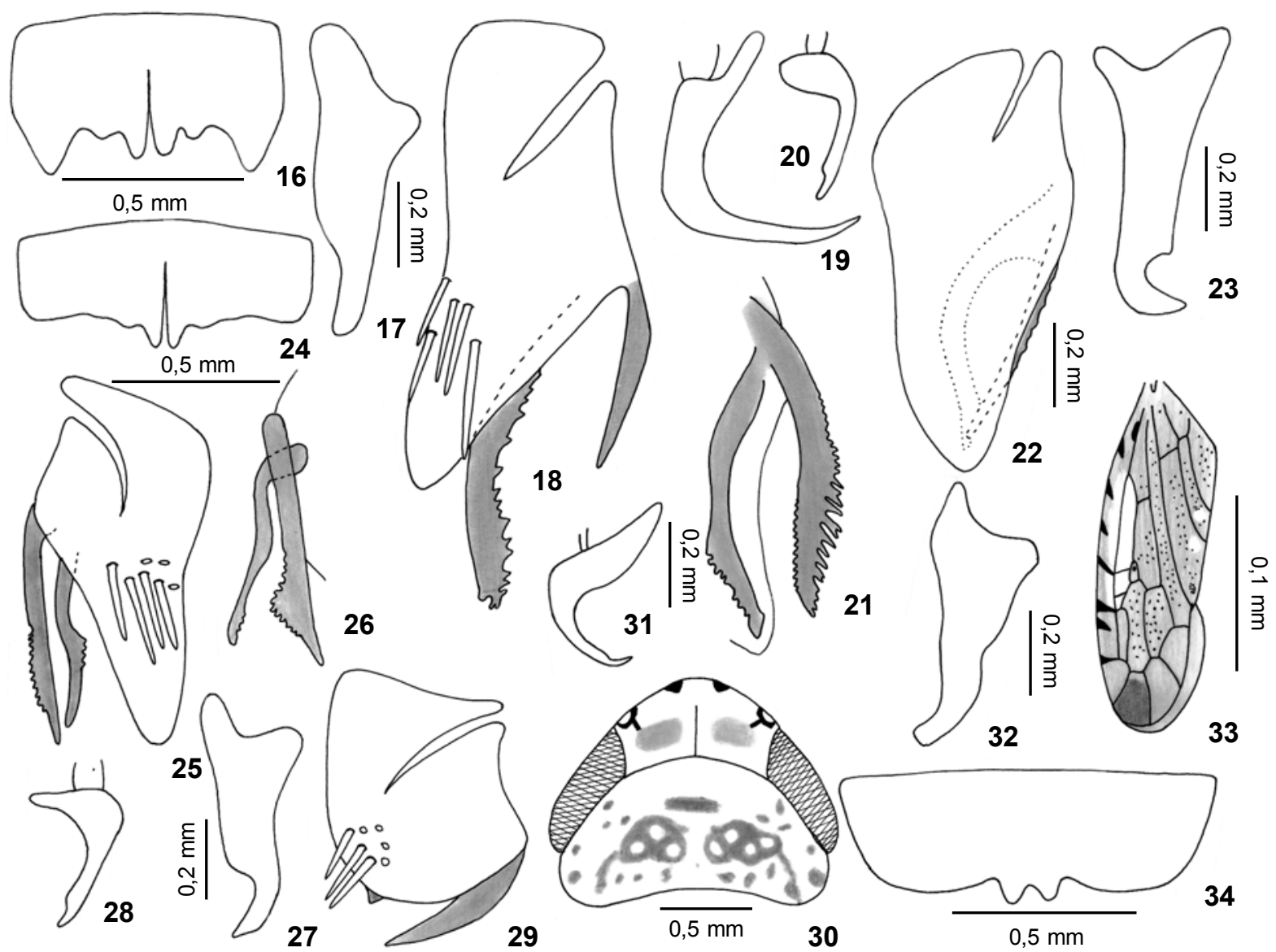

Figuras 16-34. (16-19) Taperinha compta sp. nov.: (16) sétimo esterno da fêmea; (17) estilo; (18) pigóforo, lateral; (19) edeago, lateral. (20-23) Taperinha tefeigua sp. nov.: (20) edeago, lateral; (21) apêndice pigóforo, vista interna; (22) pigóforo, lateral; (23) estilo; (2428) Taperinha assurinia sp. nov.: (24) sétimo esterno da fêmea; (25) pigóforo, lateral; (26) apêndice pigóforo, vista interna; (27) estilo; (28) edeago, lateral. (29-34) Taperinha pupejua sp. nov.: (29) pigóforo, lateral; (30) cabeça e pronoto, dorsal; (31) edeago, lateral; (32) estilo; (33) asa anterior; (34) sétimo esterno da fêmea.

\section{Taperinha assurinia sp. nov.}

Figs $24-28$

Holótipo macho. Coroa marfim com duas manchas alaranjadas sobre o disco; margem anterior com quatro pequenas manchas marrons: duas junto aos ocelos e duas medianas.

Pronoto marfim com duas manchas irregulares amareloouro sobre o disco e duas na margem anterior, alaranjadas. Asas anteriores esbranquiçadas com uma grande mancha mais ou menos triangular com sua base na margem anal e o ápice na altura da segunda célula discal, mancha esta marrom-clara com pontos marrom-escuros e esparsos, coalescentes nos bordos e duas pequenas áreas arredondadas, esbranquiçadas, junto à margem anal; margem costal com manchas triangulares marrons; células anteapicais, central e interna, pontuadas de marrom; terceira, quarta e quinta células apicais marrom-claras.

Pigóforo com dois pares de apêndices ventrais: o par proximal com a borda externa, na metade apical expandida lateralmente e irregularmente serreada; o par distal sinuoso, com a borda interna denticulada, na expansão lateral, aproximadamente no terço apical. Estilos com ápice obliquamente truncado. Edeago tão longo quanto o conetivo, levemente curvo para cima, bífido com braços paralelos.

Fêmea. Sétimo esterno com a margem posterior sinuosa com um lobo de cada lado da fenda mediana; fenda ultrapassando a metade do comprimento da placa.

Comprimento. Macho: 4,14; fêmea: 4,30.

Material examinado. Holótipo macho do Brasil. Pará: Tucuruí (Rio Tocantins, Chiqueirão), 13.IV.1981 (MPEG). Parátipos. Ibidem, 12.IV.1984, T. Pimentel leg., 1 fêmea (MPEG); Ibidem, (Saúde), 5-7. VI. 1984, T. Pimentel leg., 1 fêmea (DZUP). Etimologia. De Assurini $=$ nome de tribo Tupi habitante das margens do rio Tocantins.

Revista Brasileira de Zoologia 21 (2): 337-342, junho 2004 


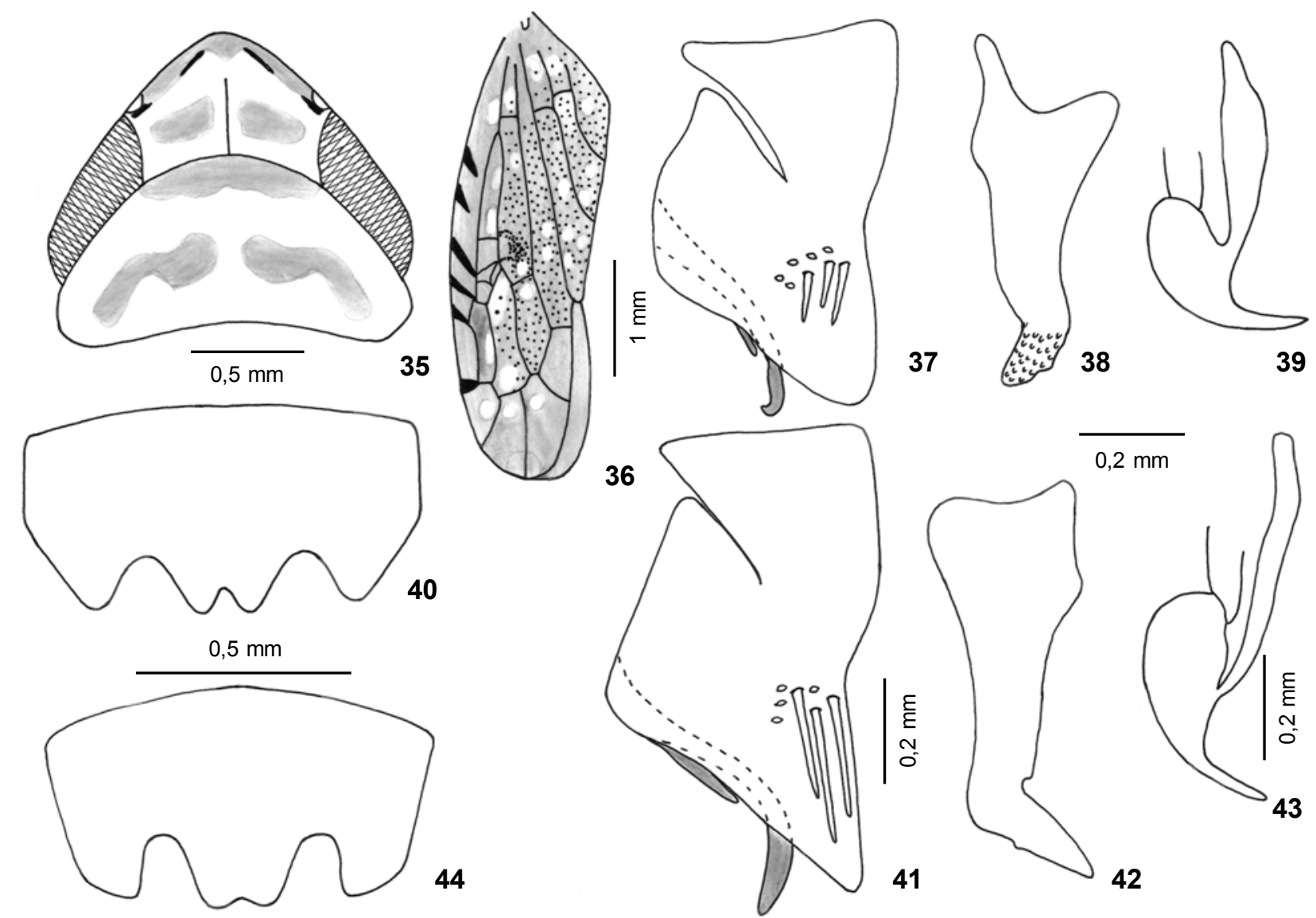

Figuras 35-44. (35-40) Taperinha freytagi sp. nov.: (35) cabeça e pronoto, dorsal; (36) asa anterior; (37) pigóforo, lateral; (38) estilo; (39) edeago, lateral; (40) sétimo esterno da fêmea. (41-44) Taperinha ourensis sp. nov.: (41) pigóforo, lateral; (42) estilo; (43) edeago, lateral; (44) sétimo esterno da fêmea.

\section{Taperinha pupejua sp. nov Figs 29-34}

Holótipo macho. Coroa marfim com duas manchas amarelas sobre o disco; margem anterior com quatro manchas marrons: duas junto aos ocelos e duas medianas.

Pronoto marfim com manchas marrons. Asas anteriores marfim com pontos dispersos marrom-escuros nas células anteapicais central e interna, segunda célula discal, célula braquial e no clavo; margem costal com manchas triangulares marrom-escuras; terceira célula apical marrom.

Pigóforo com um apêndice ventral largo e pontiagudo e um processo apical em forma de acúleo, de cada lado. Estilos digitiformes com ápice truncado. Edeago menor que o conetivo, curvo para cima com ápice bífido.

Fêmea. Sétimo esterno com a margem posterior arredondada e com um lobo de cada lado da pequena fenda mediana. Comprimento. Macho: 4,20-4,76; fêmea: 4,90.

Material examinado. Holótipo macho do Brasil, Amazo- nas: Coari (rio Urucu, $4^{\circ} 51^{\prime} 56,5^{\circ} \mathrm{S} / 65^{\circ} \mathrm{W}, 4^{\circ} 56,6^{\prime \prime} \mathrm{W}$ ), 1118.VI.1991, P. Bührnhein; N. Aguiar \& F.A. Fé leg. (DZUP). Parátipos. Ibidem, Petrobras, ROC, 5-10.II.92, 1 macho, 1 fêmea (UFAM, DZUP); Guajará (rio Ipixuna, 706'39"S, 7305' 25"W), 13-19.VI.1995, P. Bührnhein e N. Aguiar leg., 1 macho; Juruá (rio Mineruazinho, 03³4'S, 66º58'W), 13-25.I.1996, P. Bührnhein e N. Aguiar leg., 1 macho (DZUP); Marão (rio Japurá, Maguari), 26-29.X.1988. 1 macho (MPEG).

Etimologia. Tupi: pupé $=\mathrm{com}+j u=$ espinho, alusivo ao processo espiniforme do pigóforo.

\section{Taperinha freytagi sp. nov. \\ Figs $35-40$}

Holótipo macho. Coroa marfim; margem anterior com uma estreita faixa, entre os ocelos, alaranjada e quatro manchas marrons: duas junto aos ocelos e duas medianas; região discal com duas manchas alaranjadas.

Pronoto marfim; margem anterior com uma faixa trans-

Revista Brasileira de Zoologia 21 (2): 337-342, junho 2004 
versa, entre os olhos e duas manchas, sobre o disco, alaranjadas. Asas anteriores fulvas com áreas esbranquiçadas e pontos dispersos marrom-escuros nas células anteapicais central e interna, segunda célula discal, célula braquial e no clavo; margem costal alaranjada com manchas triangulares marrom-escuras.

Pigóforo com um par de apêndices ventrais sinuosos com ápices voltados para trás e um par de processos espiniformes, no ápice. Estilos digitiformes; apófises com a borda interna irregular. Edeago menor que o conetivo, globoso e curvo para cima; ápice bífido com os braços paralelos.

Fêmea. Sétimo esterno com a margem posterior escavada e com uma leve reentrância no meio.

Comprimento. Macho: 4,90; fêmea: 5,10-5,78.

Material examinado. Holótipo macho do Brasil, Acre: Porto Acre (Humaitá), 15.VI a 02.VII. 1992, Gorayeb, Pena, Henriques, Edmar leg. (MPEG). Parátipos. Ibidem, 3 fêmeas (MPEG, DZUP).

Etimologia. O nome é em homenagem ao Dr. Paul H. Freytag, da University of Kentucky, EUA.

\section{Taperinha ourensis sp. nov. Figs 41-44}

Holótipo macho. Coroa marfim; margem anterior com uma estreita faixa, entre os ocelos, alaranjada e quatro manchas marrons: duas junto aos ocelos e duas medianas; região discal com duas manchas alaranjadas.

Pronoto marfim; margem anterior com e uma faixa transversa, entre os olhos e duas manchas, sobre o disco, alaranjadas. Asas anteriores fulvas com áreas esbranquiçadas e pontos dispersos marrom-escuros nas células anteapicais central e interna, segunda célula discal, célula braquial e no clavo; margem costal alaranjada com manchas triangulares marrom-escuras.

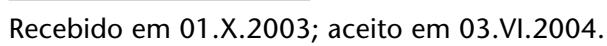

Pigóforo com um par de apêndices ventrais de cada lado: o par distal reto, voltado para frente e o par proximal maior com o ápice voltado para fora. Estilos com apófises fortemente projetadas para fora. Edeago menor que o conetivo, globoso e curvo para cima; ápice bífido com os braços paralelos.

Fêmea. Sétimo esterno com a margem posterior escavada e com uma leve reentrância no meio.

Comprimento. Macho: 4,84-5,30; fêmea: 5,40.

Material examinado. Holótipo macho do BrasiL, Rondônia: Ouro Preto do Oeste, 6-12. VII.1995, Rafael e Vidal leg. (DZUP). Parátipos. Ibidem, 6-12.VII.1995, Rafael e Vidal leg. 4 machos (INPA, DZUP); Ibidem, 22.X.1987, C. Elias leg., 1 fêmea (DZUP). Etimologia. O nome é alusivo à localidade-tipo.

\section{REFERÊNCIAS BIBLIOGRÁFICAS}

LINNAVUORI, R. 1959. Revision of the neotropical Deltocephalinae and some related

subfamilies (Homoptera). Annales Zoologici Societatis

Zoologicae Botanicae Fennicae Vanamo, Helsinki, 20 (1): $1-370$

Linnavuori, R. \& D.M. DeLong. 1978. Neotropical leafhoppers of the Bahita group (Homoptera, Cicadellidae, Deltocephalinae). Brenesia, San Jose, 14-15: 109-169.

ZANOL, K.M.R. 1988. Descrição de cinco espécies novas de Taperinha Linnavuori, 1959 (Homoptera: Cicadellidae). Revista Brasileira de Entomologia, São Paulo, 32 (3/4): 411415.

1989. Descrição de duas espécies novas de Taperinha Linnavuori, 1959 (Homoptera, Cicadellidae, Deltocephalinae). Revista Brasileira de Zoologia, Curitiba, 6 (2):255258.

1997. Uma nova espécie de Taperinha Linnavuori (Homoptera, Cicadellidae, Deltocephalinae). Revista Brasileira de Zoologia, Curitiba, 14 (3): 625-627. 